\title{
O ENSINO COMO PREMISSA PARA O DESENVOLVIMENTO DO BEBÊ NA CRECHE
}

José Ricardo Silva, José Milton de Lima

Universidade Estadual Paulista - UNESP, Presidente Prudente, SP. E-mail: ricardo.unesp@hotmail.com

\section{RESUMO}

A atuação docente em creches, especificamente com bebês de até 12 meses de idade, apresenta concepções assistencialistas que caracterizam a rotina como afazeres domésticos, focado na proteção, alimentação e higiene. Entendemos que estas características são marcas históricas que precisam ser superadas haja vista a necessidade de mediações humanizadoras que contribuam com o desenvolvimento dos bebês. Sob esta preocupação, este artigo objetiva debater a importância do ensino como prática pedagógica na creche. Na busca por este objetivo, utilizamos como aporte teórico, a teoria histórico-cultural. Os autores desta teoria nos levam a entender que, o bebê é um ser em desenvolvimento e, quando inseridos em instituição de ensino, suas relações não podem ser limitadas apenas aos cuidados físicos, faz-se necessário o ensino sistematizado que contribua com seu processo de humanização.

Palavras chaves: Bebês. Teoria histórico-cultural. Ensino.

\section{TEACHING AS A PREMISE FOR BABY'S DEVELOPMENT IN THE NURSERY}

\begin{abstract}
The teaching practice in kindergartens, specifically with babies up to 12 months of age, presents welfare concepts that characterize the routine as household chores, focusing on protection, food and hygiene. We believe that these characteristics are historical marks that must be overcome given the need for humanizing mediations that contribute to the development of babies. Under this concern, this article aims to discuss the importance of education as a pedagogical practice in the nursery. In pursuit of this goal, we will use as the theoretical, historical-cultural theory. The authors of this theory lead us to understand that the baby is a developing human being, and when inserted in an educational institution, their relations can not be limited only to physical care, it is necessary systematic teaching that contributes to the process of humanization.
\end{abstract}

Keywords: Babies. Cultural-historical theory. Education. 


\section{INTRODUÇÃO}

Ao longo do tempo, diversas pesquisas, tais como as realizadas por Campos $(1987,1989)$, Nosela (2002), Kramer (2002), Santos (2005), Kulhmann (2005, 2007), Cerisara (2010a, 2010b) e Sayão (2010) dentre outras, se propuseram a investigar e denunciar os problemas recorrentes na Educação Infantil. Tais obstáculos persistem e marcam seu avanço - obstáculos nos âmbitos legais, estruturais, de formação de professores (inicial, continuada e em serviço), entre outros. Contudo, alguns desses problemas ainda não foram superados, haja vista que resquícios históricos influenciam as práticas docentes de modo a desqualificá-las e reforçar estigmas históricos.

Embora haja, atualmente, avanços teóricos, práticos e legais que nos auxiliam, notamos que este desarranjo se torna ainda mais preocupante no que concerne ao atendimento de bebês nas creches. Esta modalidade educacional ainda enfrenta uma desvalorização social da profissão, com isso, a procura para exercê-la é baixa por não se demonstrar como um campo promissor de trabalho. Aparentemente, a atuação docente em creches, mais especificamente com bebês de até 12 meses de idade, ainda apresentam concepções assistencialistas que caracterizam a rotina como afazeres domésticos, focado na proteção, alimentação e higiene, caracterizando o trabalho docente como não diretivo, espontâneo, embasado no cotidiano, no empirismo, no conhecimento tácito e na espera pelo desenvolvimento do bebê que há de vir e que, por isto, não há trabalho pedagógico a ser realizado com ele. (CAMPOS, FÜLLGRAF, WIGGERS, 2006; SILVA, 2009; DANDOLINI, ARCE, 2009; MARTINS, 2009; RAMOS, 2011; OLIVEIRA, 2014;)

Com isso, instala-se no trabalho institucionalizado com bebês uma tendência denominada por Martins (2009) como "pedagogia da espera". Esta tendência decorre de uma incoerente percepção do próprio professor acerca de seu trabalho no berçário quando este entende que não há nada a ser feito com os bebês, além de prover suas necessidades fisiológicas de alimentação, higiene e sono, enquanto espera pelo desenvolvimento que há de vir.

Contrariando estas concepções, entendemos a importância de que o bebê seja compreendido para além dos aspectos biológicos e de suas necessidades fisiológicas. Temos clareza da necessidade e importância dessas práticas, porém insuficientes para garantir o desenvolvimento infantil. Para isso, os professores devem conhecer o desenvolvimento do bebê e seu processo de humanização e, para tal, considerar o ensino como prática pedagógica imprescindível.

Assim, este texto tem como objetivo defender o ensino como prática pedagógica do professor de bebês na creche, como pressuposto para o desenvolvimento humano. Na busca por este objetivo, nossa discussão será elaborada à luz da Teoria Histórico-cultural. Acreditamos que ao 
discutirmos a necessidade do ensino no ato pedagógico, planejado e mediado intencionalmente, estaremos contribuindo com as práticas pedagógicas desenvolvidas nas escolas infantis que buscam favorecer o desenvolvimento humano dos bebês.

\section{METODOLOGIA}

O presente artigo tem como procedimento metodológico a pesquisa denominada de bibliográfica. Segundo Lima e Mioto (2007) esta metodologia permite aos pesquisadores análises pessoais tendo como referência informações e análises a partir de um vasto campo de informações literárias. Dentre os autores pesquisados, destacamos as contribuições de Mukhina (1996) e Martins $(2009,2013)$ sobre o desenvolvimento infantil.

\section{RESULTADOS}

Para início de nossas discussões consideramos ser pertinente compreendermos o desenvolvimento do bebê, ou seja, sob quais alicerces se estruturam sua humanização.

Antes de nascer, o feto tem o seu desenvolvimento assegurado pela mãe por via do cordão umbilical. Após o nascimento ocorrem mudanças drásticas no modo de vida do bebê, por exemplo, o choro na sala de parto marca a adaptação muscular dos primeiros reflexos de respiração via pulmonar, a partir de agora, seu modo de respirar e, também, o de se alimentar serão diferentes.

A etapa imediatamente posterior ao nascimento é a única na vida do homem em que se observam em estado puro as formas inatas e instintivas de comportamento, cujo fim é satisfazer as necessidades orgânicas (de oxigênio, alimentação, calor). Essas necessidades orgânicas garantem apenas a sobrevivência da criança, mas não constituem a base de seu desenvolvimento psíquico. (MUKHINA, 1996, p. 76)

Imediatamente, manifestam-se nos bebês mecanismos reflexos não condicionados, de orientação e protetores que irão assegurar a adaptação e o desenvolvimento do organismo às novas condições de vida, diferente da intra-uterina. Uma herança biológica humana "[...] formas primitivas e inatas de comportamento, de qualquer maneira necessária para que a criança sobreviva e posteriormente atinja sua maturidade psíquica." (MUKHINA, 1996, p. 41).

Estes comportamentos inatos e primitivos "revestem" o bebê com capacidades de proteção e de orientação no espaço, portanto, necessários para sua sobrevivência. Como exemplos de reflexos de orientação, podemos citar: reflexo de sucção, reflexo de preensão, reflexo de impulso, o ato de piscar os olhos sob luz forte, assustar-se com altos sons, retrair mãos 
e pés sob novas circunstâncias, mover a cabeça em direção ao alimento que Ihe tocam os lábios, e etc. (MUKHINA, 1996).

Estas manifestações dos bebês são orientadas pelas influências externas que receberão e colocarão em exercício seus órgãos dos sentidos, seus analisadores (receptores, nervos aferentes e zonas cerebrais de elaboração de impulso e resposta), que farão a conexão entre o mundo externo e o interno do bebê, como um meio de comunicação não verbal. Serão, portanto, os seus órgãos dos sentidos (visão, audição, olfato, tato e paladar) que captarão os mais diversos estímulos e os enviarão através de conexões neurais ao córtex cerebral para serem processados, para então, formarem o psiquismo humano, ou seja, a imagem subjetiva da realidade objetiva ou, ainda, o reflexo psíquico da realidade. "Na relação entre sujeito e objeto reside, portanto, o aspecto fundante da formação da imagem subjetiva e da realidade objetiva e, para tanto, a captação sensorial do mundo desponta como requisito primário." (MARTINS, 2013, p. 122)

Desenvolvem-se, em particular, os setores responsáveis por captarem impressões externas. Esta capacidade do bebê é assegurada pelas áreas primárias do córtex cerebral, ligadas à sensibilidade ou com a motricidade. "No recém-nascido estão mielinizadas tão somente as chamadas áreas primárias do córtex, vinculadas aos órgãos da percepção que por seu próprio desígnio são esferas receptoras" (VYGOTSKI, 1996, p.293). É esta a primeira área que receberá os estímulos do meio e os enviará às demais áreas do cérebro.

É preciso ressaltar, antes de prosseguir, que o nível maturacional do cérebro do bebê não assegura o desenvolvimento dos sentidos que irão nortear sua relação em sociedade. Seu cérebro está em desenvolvimento pois, diferentemente do animal, o cérebro humano continua a se formar ainda depois do nascimento. No entanto, este órgão possui determinante função no desenvolvimento humano, pois mesmo ainda em desenvolvimento, é capaz de captar informações do mundo externo. Seu desenvolvimento é decorrente da quantidade de impressões externas que recebe a partir das experiências do bebê. Por outro lado, os setores do cérebro que não forem exercitados podem ter o desenvolvimento interrompido e até mesmo atrofiados.

A criança recebe da natureza o aparelho auditivo e os correspondentes setores do sistema nervoso preparados para diferenciar os sons da linguagem. Mas o próprio ouvido lingüístico só se desenvolve no processo de assimilação de uma determinada língua, sob a orientação do adulto, com a particularidade de que o ouvido lingüístico acaba adaptado às particularidades da língua materna. (MUKHINA, 1996, p. 41)

Nisso reside a necessidade de relações sociais humanizadoras que os bebês precisam experenciar. Isto nos leva a compreender que o desenvolvimento humano não é dado a partir da 
composição biológica, o bebê necessita de alguém que o acolha, proteja, cuide, alimente, aqueça, eduque. Sendo assim é correto afirmar que, para a teoria de Vigotski, a Psicologia Históricocultural, o bebê é "(...) "um candidato à humanização", um ser hominizado, representante da espécie homo sapiens. (PASQUIALINI, p. 75, 2013) (grifos do autor). Pois, possui todo o aparato biológico geneticamente herdado de milhares e milhares de gerações que lhe proporciona, a partir de determinadas condições, evoluir em direção ao que denominamos de humanização.

Sabemos que, de modo geral, os bebês estão cotidianamente em contato com adultos, com objetos da cultura e com outras crianças e, estas relações podem desencadear o seu desenvolvimento. No entanto, nossa preocupação reside nas relações experienciadas em instituições de educação, ou seja, de ensino onde, diferentemente da vida familiar, deve ser respaldada pelo conhecimento científico. Pois, como problematizado anteriormente, entendemos que o trabalho com os bebês não pode ser pautado na maternagem, no improviso, no conhecimento tácito. $O$ bebê é um ser em desenvolvimento, seu cérebro apresenta plasticidade e, esta capacidade precisa ser entendida para então, ser devidamente estimulado.

\section{DISCUSSÃO}

Para que os as descobertas humanas sejam apropriados pelos frequentadores da escola da infância, é preciso viabilizá-los de forma que se tornem saberes escolares e, no caso da mediação do conhecimento com os bebês, este trato com os saberes escolares, toma um patamar diferenciado em relação às outras etapas do desenvolvimento humano. Mas como trabalhar com conteúdos escolares com bebês quando estes ainda não lêem, não escrevem, não falam com o professor ou com seus pares? Antes de responder a esta questão, é importante definirmos o que entendemos por conteúdos escolares. Para isto nos apoiamos em Martins (2009, p. 94) quando esta define conteúdos de ensino como "[...] os conhecimentos mais elaborados e representativos das máximas conquistas dos homens, ou seja, componentes do acervo científico, tecnológico, ético, estético etc. convertidos em saberes escolares." Na mesma direção, complementa Saviani, os conteúdos de ensino "[...] diz respeito ao conhecimento elaborado e não ao conhecimento espontâneo; ao saber sistematizado e não ao saber fragmentado; à cultura erudita e não à cultura popular (SAVIANI, 2011, p. 14)."

Com esta definição, consequentemente outra questão se coloca: quais são as descobertas humanas que se configuram enquanto conteúdos escolares a serem trabalhados com os bebês? $\mathrm{Na}$ busca por uma resposta a esta questão, encontramos algumas considerações pertinentes inerentes ao objetivo deste trabalho. 
Para Mukhina (1996) quanto menor é a criança, mais elementares e simples serão os conhecimentos que ela poderá assimilar. Martins (2009) defende que o os conteúdos escolares não devem encerrar em si os objetivos escolares, caso contrário, seriam vazios de significados e não passariam de meras ocupações às crianças. De certo, os conteúdos escolares são aqueles que ampliam as possibilidades de controle do ser humano sobre si mesmos e sobre o mundo, ou seja, aqueles que desenvolvem as Funções Psíquicas Superiores ${ }^{1}$. Esta relação fica ainda mais clara ao levarmos em consideração que o, ao nascer, o bebê apresenta Funções Psíquicas Elementares e, socialmente poderá desenvolver Funções Psíquicas Superiores que facilitarão cada vez mais sua relação com o mundo externo e o controle sobre si. Para a autora, no trato pedagógico com o bebê, os conteúdos são entendidos como conteúdos de formação operacional (grifos do autor). Estes conteúdos devem estar sob o domínio do professor e subjazem suas propostas como saberes interdisciplinares e não são transmitidos em seu conteúdo conceitual produzindo uma aprendizagem indireta (grifos do autor). Como exemplo de conteúdos com esta natureza, destacamos a acuidade perceptiva e sensorial, domínios psicofísicos e sociais e destreza psicomotora.

Sob esta perspectiva, o trabalho pedagógico com os bebês não pode ser pautado sobre a produção, mas, sim na experimentação, na vivência significativa, na exploração, na investigação, na descoberta, na pesquisa através de todos os seus órgãos dos sentidos realizada pelo próprio bebê sob a sistematização, o olhar, a atenção, a avaliação e a intervenção de um profissional da educação. No entanto, reside no imaginário das professoras que atuam com bebês a errônea concepção de que não há tempo ou possibilidades para desenvolver atividades com bebês. Tempo este ocupado para a recepção, a alimentação, a troca, o sono, o banho, a despedida...

Ao contrário, as possibilidades estão presentes e latentes em todos os momentos do bebê na creche, desde a chegada até o momento de ir embora. É preciso ter claro que no trabalho com os bebês, toda relação estabelecida com os bebês podem ser atividades de ensino, pois todas as relações educam. Reside nesta concepção, a responsabilidade de que toda ação docente com e para o bebê deva ser antecipada e conscientemente planejada como uma atividade de ensino.

Estes autores partem do princípio de que aquilo que não faz parte da natureza humana, precisa ser ensinado, de forma que cada indivíduo singular se aproprie culturalmente de toda produção humana, em forma de uma segunda natureza. Deste modo, ao invés de pensarmos em limitações, podemos considerar a possibilidades dos bebês em estabelecer relações com o meio externo em que está inserido. E, como vimos no início deste texto, podemos afirmar que, na

\footnotetext{
${ }^{1}$ Formas complexas e superiores de comportamento onde, desprovidas das condições sociais de formação, o psiquismo humano não conquistaria, por exemplo, linguagem, escrita, cálculo, desenho, etc. (MARTINS 2013)
} 
verdade, limitadas são as práticas pedagógicas direcionadas aos bebês nas creches brasileiras quando estas se limitam a alimentação, ao banho e ao sono.

\section{CONCLUSÕES}

Assumimos neste texto o objetivo de discutir o ensino como ato pedagógico que auxilia no processo de humanização do bebê. Nossa discussão teórica nos levou a compreender, inicialmente, que o desenvolvimento do bebê é de ordem social, ou seja, que é necessário estar imerso em meio social para que seja promovido o desenvolvimento e, posteriormente, a importância da instituição educacional creche, possibilitar vivências qualitativamente diferenciadas da vida cotidiana. Para isso, os professores que atuam neste nível da Educação Básica precisam entender o seu trabalho apartado de práticas de maternagem, do improviso e do conhecimento tácito, ou seja, precisam entender cientificamente o desenvolvimento do bebê para realmente considerá-los como centro de sua prática pedagógica.

Estendemos que, ao assumir o ensino como a prática de sistematização e planejamento do que ensinar aos bebês, este será o primeiro passo que facilitarão ao bebê generalizar em sua individualidade as objetivações humanas e, num futuro próximo, analisar e diferenciar os objetos e os fenômenos culturais em suas propriedades mais específicas. À medida que crescerem e se desenvolverem, esses contatos tornar-se-ão cada vez mais elaborados, humanizando-os e provocando mudanças revolucionárias em seu desenvolvimento. Sabemos que este processo demanda muito tempo, pois torna-se necessário que a criança tenha atingido determinada qualidade psíquica através de internalizações para conseguir tal mudança. Todavia, é de suma importância o professor entender que sua relação com o bebê deve ser de qualidade humanizadora e não apenas de cuidados físicos.

\section{REFERÊNCIAS}

CAMPOS, M. M. Criança: compromisso social. In: CAMPOS, M. M (org.). Estas somos nós. São Paulo, v. 1, p. 37, 1987.

. Pré-escola: entre a educação e o assistencialismo - 1985. In: ROSEMBERG, F. (Org.) Creche. São Paulo: Cortez, 1989. p. 11-19.

CAMPOS, M., M., FULLGRAF J., WIGGERS V. A qualidade da educação infantil brasileira: alguns resultados de pesquisa. Cad Pesqui.;36 (127): 2006 p. 87-128. http://dx.doi.org/10.1590/S010015742006000100005

CERISARA, A. B. Educar e cuidar: por onde anda a educação infantil? Perspectiva, Florianópolis, v. 17, n. especial, p. 11-21, jul./dez. 1999. Disponível em: 
<http://www.periodicos.ufsc.br/index.php/perspectiva/article/viewFile/10539/10082>. Acesso em: 05. jun. 2010a.

. O referencial curricular nacional para a educação infantil no contexto das reformas.

Educação e Sociedade, Campinas, v. 23, n. 80, p. 326-34, set. 2002. Disponível em:

<http://www.scielo.br/pdf/es/v23n80/12935.pdf>. Acesso em: 05 jun. 2010b.

DANDOLINI, M. R; ARCE, A. A formação de professores de Educação Infantil In: ARCE, Alessandra; MARTINS, Lígia Márcia. Ensinando aos pequenos: de zero a três anos. Campinas, SP: Editora Alínea, 2009. 207p

KRAMER, S. Formação de profissionais de educação infantil: questões e tensões. In: MACHADO, M. L. de A. Encontros e desencontros em educação infantil. São Paulo: Cortez, 2002

KUHLMANN JR., M. Educação Infantil e currículo. In: FARIA, A. L. G. de; PALHARES, M. S. (Orgs.). Educação Infantil pós-LDB: rumos e desafios. 5. ed. Campinas: Autores Associados, 2005. p. 51-64.

2007.

. Infância e Educação Infantil: uma abordagem histórica. 4. ed. Porto Alegre: Mediação,

LIMA,T. C. S.; MIOTO, R. C. T. Procedimentos metodológicos na construção do conhecimento científico: a pesquisa bibliográfica. Rev. Katál. Florianópolis, v. 10, n.esp. P. 37-45, 2007.

MARTINS, L. M. O ensino e o desenvolvimento da criança de zero a três anos. In: ARCE, A.; MARTINS, L. M. Ensinando aos pequenos: de zero a três anos. Campinas: Alínea, 2009.

. O desenvolvimento do psiquismo e a educação escolar: contribuições à luz da psicologia histórico-cultural e da pedagogia histórico-crítica. Campinas, Autores Associados, 2013.

MUKHINA, V. Psicologia da idade pré-escolar. São Paulo: Martins Fontes, 1996.

NOSELLA, P. A linha vermelha do planeta infância: o socialismo e a educação da criança. In: FREITAS, M. C.; KUHLMANN JR., M. (Orgs.). Os intelectuais na história da infância. São Paulo: Cortez, 2002. p. 129-165.

OLIVEIRA R. P. de. Entre a fralda e a lousa: um estudo sobre identidades docentes em berçários. Dissertação de Mestrado, Programa de Pós-graduação em Estudos Culturais, Escolas de Artes, Ciências e Humanidades, Universidade de São Paulo, 2014.

PASQUALINI, J. C. Periodização do desenvolvimento p'siquico à luz da Escola de Vigotski: a teoria histórico-cultural do desenvolvimento infantil e suas implicações pedagógicas. In: MARSIGLIA A., C. (org) Infância e Pedagogia histórico-crítica. Campinas, Autores Associados, 2013.

RAMOS, C. de M. M. N. O papel da professora no desenvolvimento humano da criança pré-escolar sob o enfoque da teoria histórico-cultural. Tese de doutorado - Marília, 2011.

SANTOS, M. O. V. A identidade da profissional de educação infantil. In: GUIMARÃES, C. M. (Org.). Perspectivas para educação infantil. Araraquara: Junqueria \& Marin, 2005. p. 87-101. 
SAVIANI D. Pedagogia histórico-crítica: primeiras aproximações. 11ạ ed. rev. Campinas, Autores Associados, 2011.

SAYÃO, D. T. Não basta ser mulher... não basta gostar de crianças... "Cuidado/educação" como princípio indissociável na Educação Infantil. Educação, Santa Maria, v. 35, n. 1, p. 69-84, jan./abr. 2010. Disponível em: <http://www.ufsm.br/revistaeducacao. Acessado em: 01 de maio de 2010.

SILVA, J. C. O que o cotidiano das instituições de educação infantil nos revela? O espontaneismo X o ensino. In: ARCE, A.; MARTIS, L. M. (Orgs.). Ensinado aos pequenos. Campinas: Alínea, 2009. p. 21-50.

VYGOTSKI, L., S. Obras escogidas (vol. 4). Madrid: Visor, 1996 